\title{
Los orígenes literarios de México a través de los siglos y la función de la historiografía en el siglo XIX*
}

\author{
José Ortiz Monasterio \\ INSTITUTO MORA
}

\author{
La íntima conexión que existía hace cien años entre \\ la historiografía y la literatura obliga a reconsiderar \\ la función de la primera, particularmente en \\ su aspecto moral.
}

A Clementina Díaz y de Ovando

$\mathrm{D}$ esde hace algún tiempo he estudiado la vida y la obra de Vicente Riva Palacio (1832-1896). Actualmente estoy tratando de reconstruir el horizonte cultural en que apareció originalmente la monumental obra México a través de los siglos y me inte-

* Este trabajo ha sido realizado en una colaboración del Instituto Mora con el Seminario de Crítica Literaria de la Facultad de Filosofia y Letras de la UNAM, a cargo del doctor Jorge Ruedas de la Serna. Losp rimeros resultados del Seminario se publicarán en Ruedas de la Serna (coordinador), La misión, en prensa. resa mucho establecer con claridad el estatuto que tenía entonces la historiografia entre las diferentes ramas del conocimiento. Para un lector actual es un arcaísmo que la obra mencionada señale en la portada que está escrita por "reputados literatos", pero hay mucha razón en ello pues los autores de México a través de los siglos eran en buena medida más literatos que historiadores: Alfredo Chavero fue un prolijo dramaturgo; Riva Palacio también fue autor teatral, poeta y novelista; Julio Zárate, el menos literato de todos, no obstante fue periodista; Juan de Dios Arias fue poeta y periodista; 
Enrique de Olavarría y Ferrari fue fecundo novelista; y José María Vigil fue dramaturgo, traductor de clásicos antiguos y modernos y crítico literario.

En cuanto al tomo segundo, es decir el que escribió Riva Palacio, es indudable que hay en él una influencia evidente de las obras de Darwin y Spencer, incluso un capítulo del tomo de Riva Palacio se ha incluido en antologías del pensamiento científico en México. ${ }^{1}$ Sin embargo México a través de los siglos pertenece más propiamente a una vieja tradición que hacía de la historia una rama de la literatura, no obstante que el proceso de investigación tenía un carácter científico. ${ }^{2}$ En su época fue uno de los últimos baluartes de la historia narrativa que la escuela filosófica positivista des-

\footnotetext{
' Riva Palacio, "Razas", en Moreno, Polémi. ca, 1984, pp. 247-256. Véase también Riva Palacio, "Razas", en Trabulse, Historia, 1985, vol. IV, pp. 145-159.

${ }^{2}$ En los últimos 150 años han cambiado las definiciones de ciencia y literatura. Ahora han adquirido, por logeneral, un carácter que las hace opuestas. En 1844 no había contradicción en que una disciplina fuera una ciencia y formara parte, al mismo tiempo, de la literatura. Así, por ejemplo, Francisco Ortega se refiere a "las ciencias morales, de no menor importancia para la felicidad humana que las exactas y las físicas; $y$ las cuales forman principalmente el campo inmenso de la literatura". (Ortega, p. 110, véase nota 5). Para una visión de la historia como ciencia (y literatura) en 1844 , véase la polémica entre José María Lacunza y José Gómez de la Cortina, estudiada y publicada por Ortega y Medina, Polémicas, 1970, pp. 71-132. Nótese en particular la diferencia que señala Lacunza entre las ciencias fisicas y las morales en las pp. 126-127. Para una visión reciente del estatuto dual de la historia véase De Certau, "Historia", 1987, pp. 19-33. Por mi parte, he realizado un estudio de caso sobre este tema en Historia, 1994.
}

preció; hoy se sigue leyendo gracias, en gran medida, a esa estructura narrativa.

Considerar la historiografia como un producto literario no sólo implica conceder mayor importancia a la forma, más o menos elegante, con que esté escrita, sino que resulta indispensable ubicar la teoría literaria que el autor adopta ya que en literatura, lo mismo que en historia, la mano escribe lo que la teoría le dicta.

Los autores de México a través de los siglos, creo que podemos convenir en ello, pertenecen a una corriente literaria que puede denominarse como romanticismo nacionalista que tuvo como bandera el periódico El Renacimiento (1869) y como adalid a Ignacio M. Altamirano. Sin embargo este movimiento es la culminación de una tradición anterior (patente, por ejemplo, en los frecuentes reconocimientos que hace Altamirano al maestro Ignacio Ramírez), que produjo un corpus teórico que apenas ahora se está rescatando. ${ }^{3}$

En este trabajo quisiera contrastar México a través de los siglos con cuatro artículos relativos a la teoria literaria mexicana que datan de 1844 . Los autores de estos textos son José María Lafragua, Francisco Ortega, Guillermo Prieto y Luis de la Rosa, y fueron publicados en las revistas que en aquella época reunían a los hombres de letras más destacados.

${ }^{3}$ Esta es precisamente una de las tareas que ha emprendido el Seminario de Crítica Literaria, a cargo del doctor Jorge Ruedas de la Serna, a quien agradezco que me haya proporcionado los textos que analizaré en este trabajo. 
En primer lugar notamos que, en efecto, la historia es considerada como una rama de la literatura. Francisco Ortega inicia su ensayo "Sobre el porvenir de la literatura", 4 con estas palabras:

En ninguna de las épocas del mundo civilizado se ha cultivado la literatura con más generalidad que en la presente. La historia, la biografia, la crítica, la novela, la poesía dramática, la lírica, todos los ramos de las bellas letras se enriquecen diariamente de una manera asombrosa. $^{5}$

Por su parte Luis de la Rosa abre así su discurso sobre la "Utilidad de la literatura en México": 6

Señores: Uno de los estudios más amenos y deliciosos para nuestra alma, es el de la literatura, si comprendemos bajo esta denominación los idiomas, la oratoria, la poesía, todos los escritos inspirados por la imaginación o que son la expresión de un sentimiento, la historia y todos los ramos anexos a ella. ${ }^{7}$

Creo que estas definiciones, aunque laxas y generales, nos dan una idea clara del vasto campo que abarcaba entonces la literatura y que incluía de manera natural a la historia.

Debemos precisar que esta generación estaba construyendo ya una identidad romántica, que privilegiaba el sentimiento y la inspiración antes que

${ }^{4}$ Ortega, "Porvenir", 1844, vol. Iv, pp. 109. 112.

5 Ibid., p. 109.

"De la Rosa, "Utilidad", 1844, pp. 205-211.

7 Ibid., p. 205. el preciosismo formal, que tenía en la naturaleza del país su principal fuente de inspiración, que rechazaba la "ciega idolatría de los clásicos" privilegiados por la generación anterior, en fin, que seguía las enseñanzas de Chateaubriand y Víctor Hugo. Sin embargo el romanticismo francés fue aclimatado aquí de una manera peculiar que consistió, fundamentalmente, en sostener la estética romántica pero acompañada siempre de un fin moral. Aquí no valía el arte por el arte mismo, sino el arte para mejorar a la sociedad, de la manera que intentaron hacerlo los ilustrados del XVIII.

Es curioso que Ortega, por ejemplo, siga como modelo a Chateaubriand pero lo contradiga cuando éste asegura que la literatura decae y la humanidad camina a la barbarie. En cambio Ortega augura el "porvenir espléndido de la literatura". Es decir que sigue el modelo en ciertos aspectos estéticos (preeminencia del sentimiento sobre la forma, la naturaleza como fuente de inspiración, etc.), pero lo pone de cabeza para defender sus ideales de progreso (frente a la visión decadentista de los europeos) y de que la literatura puede contribuir al mejoramiento moral de la sociedad. ${ }^{8}$

Por su parte De la Rosa insiste varias veces en que la literatura es "el más poderoso instrumento para propagar la instrucción y la moralidad", a la vez

\footnotetext{
${ }^{8}$ Esta dinámica de doble sentido, este querer ser modernos y a la vez no querer alterar la tradición heredada es un fenómeno que rebasa el ámbito puramente literario. Al respecto, Ed. mundo O'Gorman ha escrito un libro espléndido: México, 1977.
} 
que hace una clara alusión a las novelas francesas que resultan impúdicas, asegura, "cuando el argumento de la novela se toma de las clases ínfimas, en las que, por lo común, no hay pasiones sino vicios". 9 De esta manera en México el populacho, a diferencia de Francia, quedaba impedido de ser asunto de la literatura. ${ }^{10}$

Resulta muy interesante un señalamiento de Lafragua en su discurso " $\mathrm{Ca}$ rácter y objeto de la literatura" 11 en el que enfatiza el fin moral de la literatura, mediante el artificio de contrastarla con la historiografia, a la cual sí le corresponde apegarse estrictamente a la verdad:

La literatura no es la historia. Refiera ésta en buena hora los acontecimientos tales como hayan sido; pero guárdese mucho aquélla de acabar de corromper el corazón al expresar el pensamiento de la sociedad. Pinte a ésta sin exagerarla; forme un cuadro de las costumbres para mejorarlas; y por entre los recuerdos de lo pasado y los ejemplos de lo presente deje columbrar al hombre una esperanza de felicidad para el porvenir. ${ }^{12}$

9De la Rosa, "Utilidad", 1844, p. 208.

${ }^{10}$ Es preciso considerar que hasta 1836 el llamado "populacho" tuvo una participación activa e importante en las elecciones en México; después de esta fecha se hallaron los mecanismos para nulificar esta participación que resultaba peligrosa para la elite. Quizá esto, y el recuerdo de las huestes de Hidalgo, haya influido en parte en el relativo elitismo de los personajes literarios. Sobre este asunto es invaluable la tesis doctoral de Warren, "Vagrants", 1994.

${ }^{11}$ Lafragua, "Carácter", 1844, vol. I, pp. 1-5.

${ }^{12}$ Ibid., p. 5. El concepto de este autor sobre la literatura es problemático porque aquí la deslinda de la historiografía, pero antes ha dicho
Como puede verse, aquella generación no confundía a la historiografia con la literatura de ficción; la búsqueda de la verdad en la historiografia no era algo secundario sino un asunto toral. Pero aun así quedaba comprendida dentro de la Literatura con mayúsculas. Con todo, esta contradicción no debe soslayarse; y quizá su resolución sólo pueda hallarse determinando cómo cada autor hizo frente a este problema.

Por otro lado referir "los acontecimientos tales como hayan sido" no era una tarea sencilla. En el mismo año de 1844 comenzaron a publicarse las $D i$ sertaciones sobre la historia de la República Mexicana de Lucas Alamán, uno de los muy escasos trabajos dedicados a la dominación colonial en esta época; creo que Alamán era hombre de mucha inteligencia y probidad que intentó de veras narrar "los acontecimientos tales como hayan sido". Pero su versión no fue satisfactoria para amplios sectores; se traen a colación siempre sus inclinaciones ideológicas (conservadoras), pero además de esto deben considerarse las dificultades propiamente literarias (quiero decir de composición), que presentaba el escribir un libro sobre el gobierno español en México. El problema básico consistía en que la principal justificación de la independencia era el despotismo vivido en tiempos coloniales. Esto ponía un "estigma" (como veremos que dirá Prieto más adelante) en

que la literatura es "la expresión moral del pensamiento de la sociedad", y que "cubre con sus protectoras alas a todas las ciencias y a todas las artes". 


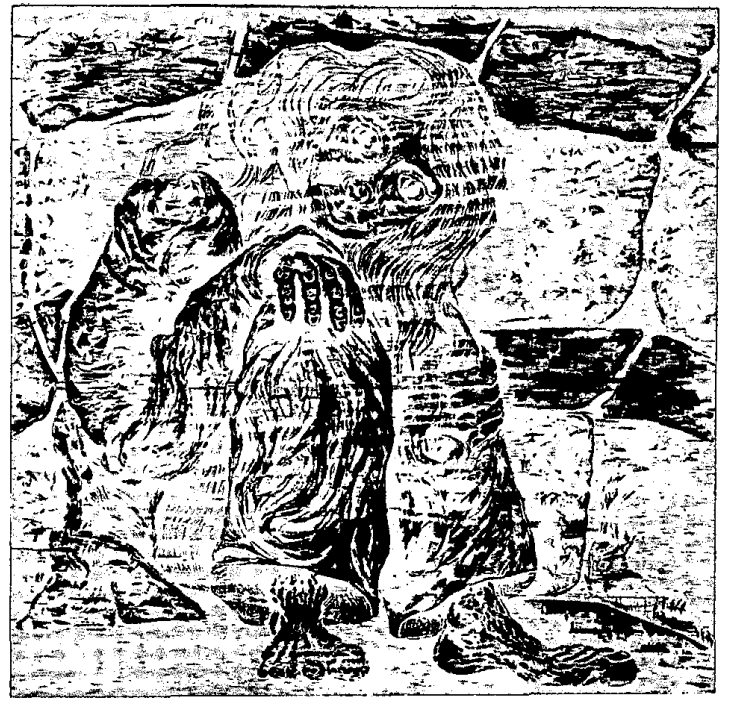

el régimen colonial que conducía a dos posturas insostenibles: la de desacreditar en forma absoluta a la colonia, como hizo Bustamante en su edición, notas y suplemento a Los tres siglos de México del padre Cavo, que conducía a una visión distorsionada que no era creíble; o bien la de tomar la defensa de la obra colonizadora de España en México, como hizo Alamán en sus Disertaciones, lo cual terminaba por negar el valor de la independencia, que en tales términos resultaba absurda, y hacía estéril el trabajo de los últimos treinta años; esta postura era igualmente insostenible. ${ }^{13}$ Para efectos de composición (y por supuesto

13 Sobre los fundamentos y contradicciones de las posturas liberal y conservadora en el siglo de interpretación) faltaba a ambas estrategias un dato fundamental: que a futuro la república triunfaría; es decir que les faltaba conocer el final de la historia.

Quisiera ahora examinar el que debe considerarse como problema central para estos autores, a saber, el de si en 1844 existía una literatura que ya pudiera llamarse propiamente mexicana. Oigamos por ejemplo la opinión de Guillermo Prieto en "Algunos desordenados apuntes que pueden considerarse cuando se escriba la historia de la bella literatura mexicana". ${ }^{14}$ De

XIX, véase la obra antes citada de O'Gorman, México, 1977.

14 Pricto, "Algunos", vol. Iv, pp. 354-360. 
los tiempos prehispánicos no se ocupa. De la colonia dice que nuestra sociedad no era "sino una fracción degradada de la de los descendientes de Pelayo". ${ }^{15}$ Y no habiendo libertad de pensamiento, ni "pueblo", no podía haber literatura. Lo único que puede elogiar de aquella "sociedad soñolienta y monástica, conjunto peregrino de señores y siervos" 16 es la diligencia de muchos sabios cronistas que "salvó del naufragio del olvido el recuerdo de un pueblo que podía competir en civilización." 17

Prieto señala que vino después la influencia nefasta del gongorismo (en el xIX el barroco era equivalente del mal gusto, de lo bárbaro, como lo refrenda Riva Palacio), ${ }^{18}$ pero el problema principal consistía en que "el poeta no tenía misión, carecía de sociedad a quien dirigirse; por mejor decir, la sociedad en que existía no tenía vida propia". ${ }^{19}$ En consecuencia, no pudo nacer entonces una literatura porque: "Faltaba al canto del bardo, espontaneidad, independencia; no había inspiración, era eco de otra sociedad gastada..." 20 Este sentido de "misión", es decir, que el literato debe contribuir al engrandecimiento y civilización de la patria, es característico del romanticis-

15 Ibid., p. 354.

16 Ibid.

17 Ibid., p. 355.

18 "Acúsase de culteranismo a los poetas mexicanos del siglo XVII; realmente puede ser fundado ese juicio, y natural que la poesía se extraviara así, llegando de la corte el ejemplo." Riva Palacio, México, 1884-1889, vol. II, p. 742.

19 Prieto, "Algunos", vol. Iv, p. 355.

${ }^{20}$ Ibid. mo mexicano y lo distingue del europeo. No bastaba que una composición fuera bella, era preciso que fuera útil. Prieto señala más adelante que los temas nacionales presentaban para el escritor colonial (y podría agregarse que en gran medida también para el escritor del siglo XIX) varias dificultades de orden político, otras de composición y otras más que iban contra el gusto de los lectores:

Referirse a los indios era expuesto, porque su historia carecía de prestigio, sus personajes habian caído en la abyección, y la depravación y el cálculo habían en un tiempo hasta puesto en duda la racionalidad de estos seres desgraciados. La historia de la conquista era en extremo monótona, y tal cual episodio de que pudiera haberse sacado partido, eran precisamente tentativas de libertad, que su reproducción se hubiera visto como un crimen. ${ }^{21}$

A mí me llama especialmente la atención la idea de que la historia colonial fuera "en extremo monótona". Pero debemos recordar que en el XIX se escribía una historia esencialmente política y, según la expresión francesa, "événementielle". Por eso Riva Palacio en su tomo sobre el virreinato repetirá lo mismo:

Vanamente se buscarán en la historia de los tres siglos que abraza el periodo de la dominación española en México, esos grandes acontecimientos que perpetua resonancia dejan en el mundo; inútilmente querrán encontrarse allí esas luchas apasionadas de los partidos

${ }^{21}$ Ibid. 
políticos o religiosos; esa efervescencia de los ánimos, tan fecunda en deslum. brantes rasgos de virtudes o de valor, que caracterizan en las épocas críticas de los pueblos las grandes convulsiones de la madurez y la virilidad.

Periodo tranquilo de crecimiento interrumpido apenas por tumultos locales y sin consecuencias, o por invasiones piráticas en las costas que no tenían más resultado que el saco o destrucción de algún puerto, la vida de la colonia se deslizaba sin ruido y sin brillo. Las noticias de la corte que una o dos veces al año llegaban con las flotas, las funciones religiosas, los actos literarios de la Universidad y algunas veces las ejecuciones de justicia o los autos de fe, eran los acontecimientos que turbaban la monotonía de aquella existencia. ${ }^{22}$

Otro punto en el que coinciden Prieto y Riva Palacio es que, para narrar el periodo colonial, había que sacar partido de las "tentativas de libertad". En efecto, las seis novelas coloniales de Riva Palacio tienen como telón de fondo un episodio relacionado con los afanes de levantar la tierra contra el dominio español: por ejemplo, el tumulto de 1624, la presencia en México de "el Tapado", la soñada revolución del irlandés Lampart, etcétera. Y en el México a través de los siglos estos episodios tienen también un papel preponderante.

En verdad, hoy es fácil decirlo, es injusto el juicio de Prieto sobre la época colonial. En cuanto a las ciencias, dice: "las controversias científicas se reducían a vergonzosos desahoXII.

22 Riva Palacio, México, 1884-1889, vol. 11, p.

Los orígenes literarios de MÉxico a traVÉs de los siglos gos de pasiones de colegio"; 23 y en cuanto a las letras: "Todos eran pastores que cuidaban borreguitos pintos, que veían sus rostros en las fuentes, que escribían en los árboles sus partidas de bautismo." 24 Era el rechazo a todo lo español. Y es que en la medida que aún existía en el país un partido monarquista, los liberales parecían considerar preciso realizar una tarea de zapa de sus fundamentos, de sus instituciones y de sus "supuestos" logros.

Vino después la guerra de Independencia y el triunfo que parecía propicio para la poesía heroica, pero entonces dice Prieto:

Las agitaciones políticas levantaron en un oleaje un trono, y los que a él se acercaban, se tornaban pigmeos y sin prestigio; se degradaron los hermosos tipos de la independencia; su cercanía a nosotros los hacía despreciables, los veíamos con sus aspiraciones, con sus ciebilidades de hombres, y la luz sobrenatural que los circuía en el combate, se disipaba, se convertía en fría realidad, y la imaginación desencantada hubiera ridiculizado o creído aduladores, los vehementes raptos del poeta. 25

Desprestigiados los indios, estigmatizados los conquistadores, degradados los héroes de la independencia, el poeta no tenía a quien cantar y por ello -según Prieto- 1821 no fue momento oportuno para el surgimiento de una literatura nacional. Era preciso prime-

\footnotetext{
${ }^{23}$ Prieto, "Algunos", vol. Iv, p. 355.

${ }^{24}$ Ibid., p. 356.

25 Ibid., p. 358.
} 
ro que se aclimataran las literaturas de otros países, que se conociera a los nuevos preceptistas de la poética y la estética. Luego surgieron en México los periódicos literarios y brilló la inspiración de Tagle, Heredia, Ortega, José María Lacunza, Calderón, Couto, Carpio, Pesado, Olaguíbel, Quintana Roo y por fin, en 1836, apareció la Academia de Letrán cuyo principal objetivo fue "procurar esa nueva era de una literatura del país." 26 Prieto termina haciendo honor a los fundadores: Juan y José María Lacunza, Manuel Tossiat Ferrer y Guillermo Prieto, que por extensión serían también los fundadores de la literatura nacional.

La opinión de los otros autores que comentamos sobre la existencia de una literatura nacional propiamente dicha es variada. Lafragua parece coincidir con Prieto: "acabamos de nacer; la literatura mexicana está, pues, en la cuna." 27 De la Rosa piensa que aún no se ha formado, pero que su formación es urgente. ${ }^{28}$ Ortega, de un modo vago, le augura un porvenir espléndido a la literatura en general. ${ }^{29}$

En cuanto a reflexión sobre la historia propiamente dicha y la manera de escribirla, es Luis de la Rosa quien más abarca. Pero no pensemos en la historia que se escribe hoy; en lugar de eso intentemos comprender la historia que a mediados del siglo XIX se creía necesaria. Dice De la Rosa:

${ }^{26}$ Ibid., p. 360 . La visión histórica del pasado literario en nuestro país que presenta Prieto es muy similar al que ofrece De la Rosa, en la obra citada; véanse en especial las pp. 210-211.

27 Lafragua, "Carácter", 1844 , p. 5.

${ }^{28}$ De la Rosa, "Utilidad", 1844, p. 210.

29 Ortega, "Porvenir", 1844, p. 112.
Nadie negará la utilidad de la historia, nadie desconocerá que, para escribirla se necesita un gran fondo de filosofia, una vasta instrucción, una erudición selecta, y una imaginación viva y ardiente. ${ }^{30}$

Pero cuidado también con el lenguaje de la época, porque entonces, al menos en este contexto, la palabra "filosofia" significaba algo bien distinto. Sigue diciendo De la Rosa:

Sin filosofia, es decir, sin el conocimiento del corazón humano, sin el estudio de sus instintos y pasiones, la historia es una relación cansada y fastidiosa, que no tiene interés alguno, porque el lector no sabe qué moralidad pueda sacar de los hechos que tan áridamente se refieren. ${ }^{31}$

Aquí interesa sobre todo destacar el papel de moralización que se le atribuye a la historia, lo mismo, según vimos antes, que a la literatura en general. De nuevo tenemos aquí la idea de que el escritor, de historia en este caso, tiene una misión moral que cumplir en la sociedad; no se trata de un simple trabajo "científico". Por otro lado tiene razón Rosa en que se necesita experiencia en el mundo y conocimiento del ser humano para historiar; como dicen los anglosajones: History is an old man's sport.

Por otra parte De la Rosa le pide al historiador una vasta instrucción que incluya el conocimiento de la geografia, la historia natural, la astronomía,

30 De la Rosa, "Utilidad", 1844, p. 209.

${ }^{31}$ Ibid., pp. 209-210. 
"algunas nociones" de ciencias exactas, la estadística, la legislación, "las opiniones y sistemas religiosos", sin faltar, por supuesto, la cronología.

Mas todos estos conocimientos no sirven de nada si el historiador carece de luces: "Pero sin crítica, sin luces para discernir la verdad o la falsedad de los hechos, la historia no puede ser más que una fábula o una novela." 32

En cuanto a las fuentes a que debe acudir el historiador son necesarias: "la mitología del país, sus fábulas, sus tradiciones, sus crónicas, las más importantes memorias de la época, la bibliografia, las obras de los historiadores que le han precedido y la crítica que se ha hecho de estas obras". ${ }^{33}$ Y a esto habría que añadir los idiomas del país, su literatura y las biografias de sus personajes célebres.

Todo esto suena a lugar común, pero en este punto De la Rosa hace énfasis en el carácter literario de la historiografía, al señalar la importancia de que el historiador conmueva los corazones, es decir los sentimientos. Creo que vale la pena citar todo el párrafo:

Pero todavía si a más de tanta instrucción y erudición, y el grande talento que se necesita para aprovechar tan inmenso caudal de luces, no posee el historiador una imaginación viva y una ardiente fantasía, los cuadros de la historia serían inanimados y no dejarían impresión alguna en el espíritu de los lectores, ni conmoverían el corazón profundamente. Es cierto que la historia no debe ser sino la relación fiel de los

32 Ibid., p. 210.

33 Ibid. hechos y su más verídica exposición; pero la imaginación es necesaria para dar a los hechos que se refieren y a las escenas que se describen, ese tinte de verdad, ese colorido de vida, ese tono dramático que es necesario para dar interés a los hechos que se refieren y hacer que se graben en la memoria. ${ }^{34}$

La interpretación de este texto no es sencilla, porque actualmente relacionamos directamente la objetividad con la verdad, y la fantasía con la ficción. Y por eso puede parecernos una contradicción el sostener que la imaginación aporta, precisamente, "ese tinte de verdad"; es decir, hace verosímil lo que de otro modo, aunque fuera un hecho irrecusable, podría no parecerlo. De modo que para De la Rosa el historiador no puede detenerse en la simple narración de la verdad, es pre. ciso que la haga verosímil. Y esto se logra gracias al "colorido de vida", al "tono dramático" que se le puede dar a la historia si se tiene una buena formación literaria. Y el objetivo final no es que el autor simplemente se adorne, sino "dar interés a los hechos que se refieren y hacer que se graben en la memoria"; es decir que la misión didáctica del historiador aparece de nuevo como su principal razón de ser.

La conclusión de De la Rosa apunta a la necesidad de crear una literatura nacional:

No se llegará a conocer en México toda la importancia de la literatura, su influencia en la civilizaciön y en el engrandecimiento de la patria, hasta que

${ }^{34}$ Ibid. 
se llegue a formar una literatura verdaderamente nacional. ${ }^{35}$

Aquí, a mi parecer, De la Rosa sintetiza los afanes de los intelectuales en las décadas de 1840 y 1850 . Estaban convencidos de que una literatura con carácter nacional, que incluía por supuesto a la historia, podría ser de gran utilidad "en la civilización y en el engrandecimiento de la patria." Por desgracia, ésta aún no se había formado en el sentido de que tuviera un carácter distintivo, que fuera diferente de un modo evidente de la española. Esto no quiere decir que no hubiera autores y libros que pudieran caracterizarse como netamente mexicanos (baste mencionar a Lizardi o al doctor Mora), pero hacía falta que estos primeros pasos se convirtieran en un amplio movimiento que llevara las nuevas ideas sobre la historia, el buen gusto, la moral, la nueva patria, etc. a todas partes del país y que contara con el apoyo decidido del Estado. Al parecer, la gran aportación de los literatos de esta época consistió en ofrecer una idea de la nacionalidad más avanzada, aunque fuera en términos de proyecto, que la que podía deducirse de la situación política y económica imperante. Crearon, por así decirlo, una realidad "virtual" que contribuyó eficazmente a actualizar esa realidad inventada.

Podría objetarse que una golondrina no hace verano, que algunos artículos publicados en las revistas literarias de la capital no llevaron su mensaje sino a unos cuantos sabios. Pero creo que esto merece ser considerado con

35 Ibid. detenimiento. En efecto la población indigena, que era mayoría, dificilmente se interesó en estos textos; no hablamos pues de una lectura masiva. Pero estas revistas, que publicaban traducciones, poesías, ensayos literarios y de divulgación tecnológica y científica estaban muy bien hechas. Conocían a su público y lograban ofrecerle un producto que combinaba perfectamente lo bello y lo útil, la distracción con la instrucción. Las revistas se coleccionaban y se encuadernaban, permaneciendo así por mucho tiempo al alcance de los lectores. Y el corto número de éstos representaba, sin embargo, un panorama más halagüeño que el que se había conocido en épocas anteriores. Así lo señala en su artículo Francisco Ortega:

El empleo de escritor [antes de la Revolución Francesa] no era un oficio, porque no era muy grande el número de las personas que se ocupaban en la lectura; mas a proporción de que éste ha ido creciendo se ha aumentado el gremio de los poetas, historiadores y romancistas, sucediendo con las obras literarias lo que con algunos artículos de comercio, como el café, el azúcar y el tabaco, que siendo al principio efectos de puro lujo se han convertido después en objetos de necesidad, y aumentándose su demanda, se ha aumentado igualmente su producción. ${ }^{36}$

Por otro lado la industria editorial mexicana había mejorado la calidad de sus productos y abatido su costo. La nueva mercadotecnia también era cosa de admirar, y un editor como Ignacio

\footnotetext{
${ }^{36}$ Ortega, "Utilidad", 1844, p. 109.
} 
Cumplido podía preciarse, precisamente en el año de 1844 en que se publicaron los artículos que comentamos, de poder distribuir sus libros en más de un centenar de localidades dentro y fuera del país, que incluían poblaciones que uno no creería con. sumidoras de libros, como Chalchihuites, Mazapil, Nieves, Pinos, Tepecoacuilco, Villanueva y Zinapécuaro. ${ }^{37}$

Otro medio de difusión de los materiales escritos era la lectura en voz alta, a la cual me he referido en otro trabajo, ${ }^{38}$ que permitía a los iletrados y a los niños enterarse del contenido de los libros; era a la vez un medio de propagar la utilidad práctica de la lectura. Por ello es sumamente vago apelar al alto índice de analfabetismo, pues la escena clásica del boticario leyendo a los parroquianos era algo que de diversos modos se realizaba cotidianamente, tanto en los hogares de la modesta clase media y en las grandes casas, como en los conventos y en los cen. tros de trabajo. Y no debe extrañarnos, más bien lo que resultaba raro entonces era la lectura en silencio y en solitario. La lectura en voz alta no está bien documentada precisamente por ser la forma natural de leer; sin embargo San Ambrosio, según cuenta San Agustín, de acuerdo con la versión de Borges, causó admiración entre sus contemporáneos cierto día que se le vio leer sin mover los labios, en silencio, aunque nadie dudó de que fuera cosa santa y buena. ${ }^{39}$

${ }^{37}$ De Fossey, Viaje, 1844, pp. 9-12.

38 Ortiz Monasterio, "Lectura", 1993.

39 Borges, "Culto", 1987, p. 714.

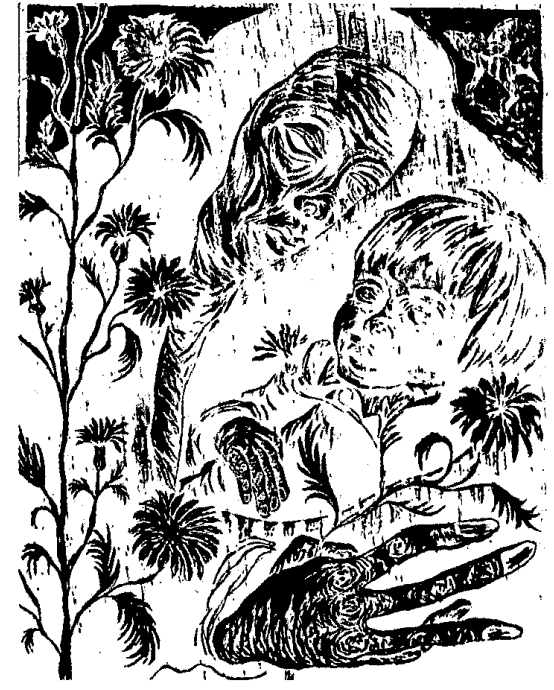

La lectura en el siglo xIx aún presenta incógnitas que es importante aclarar y para ello contamos con la base de sólidos trabajos. ${ }^{40}$ Lo que quiero enfatizar aquí es que los artículos analizados en este trabajo eran para el consumo de una elite, porque la masa de indígenas y pobres de las ciudades no tenía acceso a ellos aunque pienso que debe evaluarse con cuidado la magnitud de esa elite pues podría resultar que no sea tan pequeña como se suele creer.

Por mi parte sostengo que estos artículos circularon ampliamente y tuvieron un favorable impacto en el público lector. Las doctrinas que sostenían

${ }^{40}$ Seminario, Historia, 1988. 
hicieron escuela y, veinte años después, se convirtieron en esa eclosión literaria (e historiográfica) que siguió al triunfo republicano de 1867 , donde, gracias a los esfuerzos y a la teoría elaborada por la generación anterior, se pudo publicar mucho porque ya se tenía una brújula, un rumbo y un sentido que dar a la tarea del escritor. En el ámbito historiográfico la culminación de este proceso es México a través de los siglos, que mantiene el estatuto literario de la historiografia, recoge la estafeta nacionalista, ensalza la independencia como el valor supremo de la patria y a la vez da cuenta de la construcción del Estado en el siglo XIX. Con un Estado más fuerte, con la independencia asegurada, se pudosuperarademás el trauma de los abuelos que les impedía aceptar como parte integral de nuestra historia al periodo colonial: he aquí una contribución importantísima de Vicente Riva Palacio, pero siempre dentro del marco de la herencia intelectual mexicana. Por todo ello considero que los orígenes literarios de México a través de los siglos deben buscarse en la teoría literaria que se desarrolló en México, cuando menos, a partir de la década de 1840. El punto en el que Riva Palacio se aparta de la teoría literaria mexicana es en su visión auténticamente mestiza, que le permite valorar como contribuciones positivas las actuaciones de tipos y sectores sociales más bajos, que están ausentes en la mayoría de las producciones literarias del siglo XIX. Y que, a manera de hipótesis, se puede sostener que la función que intentaba cumplir esta obra era la misma que preconizaba la teoría en que se apoyaba: dar a conocer el pasado pero con un fin "moral"; no se trataba de mostrar al lector la verdad a secas sino de un modo que cumpliera una función integradora, que reforzara los valores nacionales y por encima de todos la independencia. Esto implica que no se debe aplicar otro criterio de verdad a esa obra, pues sería lo mismo que pedirle que hubiera sido publicada en otra época. No se trata pues de señalar en qué se equivocó o falseó la verdad Riva Palacio, sino en entender su sistema de pensamiento y en evaluar el impacto de su obra.

Casi sobra decir que la creación de una literatura nacional y la de un Estado nacional fueron procesos paralelos que se apoyaron mutuamente. Los gobiernos ilustrados apoyaron cuanto fue posible la educación y la publicación de obras de mérito; el de Santa Anna, por ejemplo, dio su nombre al "gran" teatro de la capital. En todo caso es preciso analizar con detenimiento las acciones de cada régimen, pues parece haber un proceso aglutinador y centralizador que, más allá de las banderas de partido, crea y fomenta instituciones que permiten al Estado integrar, orgánicamente, a grupos intelectuales de mucho peso.

Y los grandes actos académicos, entonces como ahora, se celebraban ante la presencia de los jefes de gobierno. Por ejemplo uno de los artículos que hemos comentado en este trabajo, el de José María Lafragua, fue leído en el recién fundado Ateneo Mexicano, allí:

El señor presidente pronunció un discurso inaugural, en que manifestando 
extensamente los progresos y estado actual de las ciencias en la república, demostró la necesidad que de protegerlas tienen los gobiernos para cumplir los deberes que les impone la sociedad, que no puede ser libre ni dichosa sino cuando la sabiduría, ocupando el mismo asiento que el poder público, es protegida por éste y le presta a la vez su ayuda y patrocinio. ${ }^{41}$

Me parece, en consecuencia, que el estudio de la formación del Estado mexicano en el siglo XIX debe tener muy en cuenta el proceso de inven. ción de la literatura nacional. Y debe ser vista no como un mero reflejo ideológico de otros procesos supuestamente más reales. No, la literatura y como parte de ella la historiografia es un elemento activo que sigue un ritmo propio, a la vez que interactúa con otras esferas, con otros procesos. En aquellos tiempos tan difíciles la publicación de una revista literaria no estaba fuera de lugar, más bien era la demostración de que, en medio de todo, una incipiente - pero bien meditadacultura mexicana existía y se desarrollaba. En medio del caos político y administrativo, la edición de una gramática era un llamado al orden, era apelar al cumplimiento de las reglas que aun el lenguaje debía seguir. Por eso no fue una ociosidad, ni una minucia, la discusión en torno a si la palabra México debía escribirse con $\mathbf{j}$ o con $x$, sino una manera más de apropiarse de la realidad, de mexicanizarla.

No tengo más conclusión que mi admiración enorme por Francisco Or-

${ }^{41}$ Lafragua, "Carácter", 1844, p. 1. tega, Luis de la Rosa y Guillermo Prieto. Sólo una palabra de agradecimiento al doctor Jorge Ruedas de la Serna, en cuyo seminario y gracias a cuyas enseñanzas pude realizar este trabajo; y otra idéntica para mi maestro el doctor Álvaro Matute, quien compartió conmigo sus ideas sobre el estatuto literario de la historiografia.

\section{BibLIOGRAFÍA}

-Borges, Jorge Luis, "El culto de los libros", en Jorge Luis Borges, Obras completas 1923-1972, Emecé Editores, Buenos Aires, 1987.

-De Certau, Michel, "La historia, ciencia y ficción”, en Historias, núm. 16, eneromarzo 1987, pp. 19-33.

-De Fossey, Mathieu, Viaje a México (prospecto), Imprenta de Ignacio Cumplido, México, 1844.

-De la Rosa, Luis, "Utilidad de la literatura en México", El Ateneo Mexicano, México, 1844 , pp. 205-211.

-Lafragua, José María, "Carácter y objeto de la literatura", discurso pronunciado en la inauguración del Ateneo Mexicano el 25 de febrero de 1844, El Ateneo Mexicano, vol. I, pp. $1-5$.

-O'Gorman, Edmundo, México. El trauma de su historia, UNAM, México, 1977.

-Ortega y Medina, Juan A. (comp.), Polémicas y ensayos mexicanos en torno a la historia, notas e índices de Eugenia W. Meyer, UNAM, Instituto de Investigaciones Históricas, México, 1970. Véase especialmente: "Discurso y cartas sobre varias reformas que parece deben hacerse en el método de algunos de nuestros estudios epistolar y científicos (polémica entre José Gómez de la Cortina y José María Lacunza).

-Ortega, Francisco, "Sobre el porvenir de la literatura", discurso leído en el Ate- 
neo Mexicano el 23 de abril de $1844, E l$ Ateneo Mexicano, vol. IV, pp. 109-112.

-Ortiz Monasterio, José, Historia y ficción. Los dramas y novelas de Vicente Riva Palacio, Instituto Mora / Universidad Iberoamericana, México, 1994.

"La lectura en familia en el siglo XIX", Coloquio Familia y Vida Privada en la Historia de Iberoamérica, El Colegio de México/Instituto de Investigaciones Sociales-unam, México, 4 de mayo de 1993.

-Prieto, Guillermo, "Algunos desordenados apuntes que pueden considerarse cuando se escriba la historia de la bella literatura mexicana", El Museo Mexicano, vol. IV, pp. 354-360.

- Riva Palacio, Vicente, México a través de los siglos, Ballescá, México, 18841889 , vol. II.
"Razas y castas de México", en Elías Trabulse, Historia de la ciencia en México. Estudios y textos, Fondo de Cultura Económica, México, 1985, vol. IV. "Las razas indígenas", en Roberto Moreno, La polémica del darwinismo en México: siglo XIX. Testimonios, UNAM, México, 1984.

-Ruedas de la Serna, Jorge, (coord.), $L a$ misión del escritor. Ensayos mexicanos del siglo $X I X$, Centro de Estudios Literarios, Instituto de Investigaciones Filológicas, México (en prensa).

-Seminario de Historia de la Educación en México, Historia de la lectura en México, El Colegio de México/Ediciones El Ermitaño, México, 1988.

-Warren, Richard, "Vagrants and Citizens: Politics and the Poor in Mexico City, 1808-1836", University of Chicago, 1994. 